\title{
Linking Data Choices and Context Specificity in Life Cycle Assessment of Waste Treatment Technologies: A Landfill Case Study
}

\author{
Henriksen, Trine; Astrup, Thomas Fruergaard; Damgaard, Anders
}

Published in:

Journal of Industrial Ecology

Link to article, DOI:

10.1111/jiec.12709

Publication date:

2018

Document Version

Peer reviewed version

Link back to DTU Orbit

Citation (APA):

Henriksen, T., Astrup, T. F., \& Damgaard, A. (2018). Linking Data Choices and Context Specificity in Life Cycle Assessment of Waste Treatment Technologies: A Landfill Case Study. Journal of Industrial Ecology, 22(5), 1039-1049. https://doi.org/10.1111/jiec.12709

\section{General rights}

Copyright and moral rights for the publications made accessible in the public portal are retained by the authors and/or other copyright owners and it is a condition of accessing publications that users recognise and abide by the legal requirements associated with these rights.

- Users may download and print one copy of any publication from the public portal for the purpose of private study or research.

- You may not further distribute the material or use it for any profit-making activity or commercial gain

- You may freely distribute the URL identifying the publication in the public portal 


\section{Linking data choices and context specificity in LCA of waste treatment technologies: A landfill case study}

Trine Henriksen *, Thomas F. Astrup, Anders Damgaard

Department of Environmental Engineering, Technical University of Denmark, Bygningstorvet 115, 2800 Kgs. Lyngby, Denmark.

*) Address correspondence to: trinhen@env.dtu.dk

NOTE: This is the authors' version of a work that was accepted for publication in Journal of Industrial Ecology. Changes resulting from the publishing process, such as peer review, editing, corrections, structural formatting, and other quality control mechanisms may not be reflected in this document. Minor changes may have been made to this manuscript since it was accepted for publication. A definitive version is published in Journal of Industrial Ecology, 2017, doi: 10.1111/jiec.12709” 


\section{Summary}

To generate meaningful results, life cycle assessments (LCAs) require accurate technology data that is consistent with the goal and scope of the analysis. While literature data are available for many products and processes, finding representative data for highly site-specific technologies, such as waste treatment processes, remains a challenge. This study investigated representative life cycle inventory (LCI) modeling of waste treatment technologies in consideration of variations in technological level and climate. The objectives were to demonstrate the importance of representative LCI modeling as a function of the specificity of the study, and to illustrate the necessity of iteratively refining the goal and scope of the study as data is developed. A landfill case study was performed where 52 discrete landfill datasets were built and grouped to represent different technology options and geographical sites, potential impacts were calculated, and min-max intervals were generated for each group. The results showed decreasing min-max intervals with increasing specificity of the scope of study which indicates that compatibility between the scope of study and LCI model is critical. Hereby, this study quantitatively demonstrated the influence of representative modeling on LCA results. The results indicate that technology variations and sitespecific conditions (e.g. the influence of precipitation and cover permeability on landfill gas generation and collection) should be carefully addressed by a systematic analysis of the key process parameters. Therefore, a thorough understanding of the targeted waste treatment technologies is necessary to ensure appropriate data choices are made within the boundaries of the defined scope of the study.

\section{Introduction}

Representative data choices are crucial for reliable life cycle assessment (LCA) in decisionmaking. However, previous studies on LCA of waste treatment technologies have revealed widespread use of inventory data that do not appropriately represent the case studies in question (Laurent et al. 2014; Astrup et al. 2014). For example, more than half of published LCAs on waste incineration do not describe the specific technology applied for air pollution control, preventing verification of inventories (Astrup et al. 2014). Representativeness is a data quality aspect linked with uncertainty as data ranges are often needed to appropriately represent the technological, geographical and temporal scope of study. The term "context” will be used throughout instead of "scope", because the focus is on the definition specifying the spatial and technological coverage of the study, and not on the other elements of the scope definition (ISO 2006). To enhance the 
reliability of LCA results, authors have suggested uncertainty analysis methods targeting both aleatory and epistemic uncertainties (e.g. Heijungs 1996; Heijungs and Kleijn 2001; Heijungs and Huijbregts 2004). For instance, Heijungs (1996) suggested to locate upper and lower parameter values to calculate min-max intervals. Min-max intervals were used to provide more robust result interpretation for a product-LCA, where multiple data choices were implemented in the life cycle inventory (LCI) of non-specific disposable beverage cups (Van der Harst and Potting 2014). Representativeness relates to the context of the study, hence, it is a contextual data quality aspect (Weidema and Wesnæs 1996). Thus, the specificity of the study context influences the required level of detail of the LCI. Olivetti et al. (2013) investigated the influence of the context specificity by quantifying the spread in the LCI of metal production corresponding to the level of knowledge about the material type. The authors suggested a method to identify the subset of available datasets that represents the specificity of the study. In addition, Bawden et al. (2016) leveraged the 'amount of information' in LCA by linking the LCI results to the level of knowledge about the system boundary, resulting in larger spreads in $\mathrm{kg} \mathrm{CO}_{2}$-eq. for lower levels of knowledge. These approaches only function if the target data, i.e. the data representing the process one wishes to model (Canals et al. 2011), lie within the obtained spread; a false sense of certainty may be obtained if the target data are located outside of the spread. In accordance with ISO (2006), collection of data is iterative and further data collection is prioritized via analyses in the result interpretation phase. Discernibility analysis and other sensitivity and uncertainty analyses are methods to identify decisive parameters in comparative LCA studies, and, hereby, to prioritize further data collection (Heijungs and Kleijn 2001). However, the outcomes of the first LCA iteration may be biased if the available data are incomplete or the boundary conditions, age, and technology level deviate from the goal and scope definition. An inappropriate first data collection, which is only partly representative of the entire study context, may result in only the lower end of an appropriate data range being represented, causing underestimation of the contribution from a particular process. Sufficient understanding of the processes in question is thus essential in the initial data collection.

On the issue of data representativeness in LCA, there are still technical domains with challenges, for example the domain of waste treatment technologies. As pointed out in Laurent et al. (2014) and Astrup et al. (2014), specific characteristics of waste treatment technologies still pose challenges regarding representative LCI modeling. Waste treatment technologies cover a range of processes that vary across sites due to their dependency on variables such as local waste composition, level of technological development, local energy supply, and climate. To exemplify the relevance of 
technological representativeness, Merrild et al. (2008) showed that the ranking of incineration versus recycling of paper waste is influenced by the specific technology configuration of the two treatment alternatives (e.g. the automation level of the recycling facility). An example of geographical representativeness was provided by Yang et al. (2015), who showed that the leachate generation from Chinese landfills of similar technology levels differed among regions due to variations in the input waste composition and climatic conditions. Other examples of the relevance of representative foreground modeling of waste treatment technologies include direct methane emissions from landfilling of organic waste, influenced by the efficiency of landfill gas collection via pipes and liners (Christensen 2011), and process-specific air emissions from waste incineration (e.g. dioxins, particles, and nitrogen oxides) that depend on the installed flue gas treatment (Damgaard et al. 2010).

For waste treatment technologies - and other technical domains with large variations across sites - further work into representative LCI modeling is needed. This article aims to investigate representative LCI modeling of waste treatment technologies while considering inherent variabilities of the technologies and the study context. Specific objectives are to i) determine the importance of using representative LCI models and making data choices that are consistent with the specificity of the study context, and ii) determine whether and how the goal and scope of the study should be refined based on the obtained data. As an example of LCA of waste treatment technologies, a case study on landfilling of household waste is conducted. Landfilling is a complex process, and is therefore considered suitable to represent different elements of potential variabilities of waste treatment technologies. This article is structured by first describing the general approach, secondly applying it to the case study, and finally discussing the outcomes in relation to representative LCI modeling.

\section{Methodology}

\section{General approach}

The general approach used in this study is illustrated in figure 1 as a list of steps $\mathrm{A}, \mathrm{B}$, and $\mathrm{C}$. The steps are consistent with standard LCA procedures including goal and scope definition, LCI analysis and life cycle impact (LCIA) assessment (ISO 2006). Focus of this study is on representative data collection and inventory modeling in step B1 and B2, relative to the specificity of the study context defined in step A. In B1, the groupings are those technology configurations and 
geographical locations that are likely to occur, considering the specified context and inherent variability of the waste treatment technology. A certain context specificity expresses a level of knowledge about the system, and an increase in specificity involves additionally known parameters (similar to specification level 1-5 in Olivetti, Patanavanich, and Kirchain 2013). Therefore, the number of likely technology configurations and geographical locations will decrease with increasing context specificity. In B2, data is collected to build the different waste treatment inventories within each grouping. The inventories are built as discrete datasets expressing choices of e.g. waste treatment technology type, location and process efficiencies. Step B requires an understanding of the waste treatment technologies at process level, as well as available data and information about expected values of key parameters. In step C, the LCIA results are calculated for each dataset after which sets of results are grouped according to the grouping in B1, enabling the development of min-max intervals for each group. Highly specific study contexts with only one representative dataset result in point values instead of min-max intervals. The point values appear to imply highly certain results, but it should be considered that single parameter uncertainty has not been included in this study. Parameter uncertainty should in principle be included to enhance robustness (e.g. Bisinella et al. 2016 and Gregory et al. 2016), but was excluded from this study to focus on the potential spread of discrete data choices made by the LCA practitioner. To some extent, parameter uncertainties were addressed as discrete choices of parameter values for continuous data, such as different technical efficiencies and climatic conditions (e.g., precipitation and temperature). Other choices in the model were truly discrete, such as the type of landfill gas treatment method and leachate discharge recipient.

\section{Steps}

A: Specify geographical and technological context of study

B1: Define groupings representing likely technology configurations and locations within the specified context

B2: Build discrete datasets for the technology configurations and locations within each grouping

C: Calculate potential impacts per discrete dataset, form sets of results equal to the groupings, and calculate min-max intervals for the sets of results

\section{LCA phase}

A: Goal and scope definition

B: Life cycle inventory analysis

C: Life cycle impact assessment

Figure 1 General approach applied in this study as a list of steps A, B, and C. The relevant LCA phases are given. LCA $=$ life cycle assessment.

\section{Framework of landfill case study}


A case study of landfilling of residual household waste was conducted, starting from the waste being received at the landfill. The functional unit was landfilling of a reference flow of $1000 \mathrm{~kg}$ waste with a temporal coverage of 100 years from the time of disposal. Mechanistic process modeling was applied in contrast to Olivetti, Patanavanich, and Kirchain (2013), who applied aggregated data from databases. Focus was on foreground modeling relative to the technological and geographical study context, while background data choices, e.g. marginal energy choices and temporal coverage, were not varied. In addition, the input waste composition was not varied. Waste composition is a geographical parameter, but this study focuses on geographical parameters representing climatic conditions. The fractional waste composition was based on Møller et al. (2013) and the physico-chemical composition was based on Riber et al. (2009), both sources representing Denmark. The chosen temporal coverage of 100 years is important, especially concerning slowly degradable and long-term leaching components. The temporal coverage of 100 years was chosen because data availability decreases for landfill time spans longer than 100 years (Manfredi et al. 2010). The marginal heat and electricity mixes of the background model were kept constant even though these can significantly influence LCA results. Energy and resources to construct the landfill were included.

A dedicated LCA model for waste treatment technologies, called EASETECH, was applied (Clavreul et al. 2014). Only secondary data based on literature and expert judgements were used, as the purpose was to compare the use of site-specific versus aggregated data. All landfill processes represented reactor landfills, i.e. engineered landfills with technical measures to control landfill gas and leachate generation (Christensen 2011). Two types of reactor landfills were included; a conventional reactor and a bioreactor landfill, the latter with enhanced gas generation from leachate recirculation (Christensen 2011).

Potential impacts were calculated for impact categories recommended by the European Commission (2010). Here, results for global warming (IPCC 2007) and human toxicity, carcinogenic (Rosenbaum et al. 2008), are illustrated and discussed. However, 14 impact categories were included in total, and an overview of all 14 impact categories, impact assessment methods and normalization references are listed in Supporting Information section 1.1.

\section{Process modules and key parameters}


The landfill model was built as a sequence of process modules as illustrated in figure 2. Foreground processes in the landfill facility were modeled mechanistically, whereas black box processes [vertically aggregated processes (UNEP 2011)] were applied in the background modeling, e.g. upstream production of landfill construction materials. The entire LCI is documented in Supporting Information section 1. Mechanistic foreground modeling ensured consistency in assumptions and system boundaries. Furthermore, it enabled inclusion of cascading responses between the processes, e.g. the link between amounts of gas generation and gas collection. Seven landfill and leachate process modules were included: landfill gas generation, collection, oxidation and treatment; and leachate generation, collection and treatment. Key parameters were varied for the names in bold in figure 2, leading to multiple module alternatives. Cross-combinations of the module alternatives enabled the generation of discrete landfill datasets with varying technological and geographical contexts, modeled as different technology configurations and climatic conditions. Based on a total number of 576 module combinations, 52 landfill datasets were considered technically feasible. The combination approach and final selection of feasible landfills are documented in Supporting Information section 2. The processes are distinguished as predominantly controlled by geographical parameters, technological parameters or a combination, as illustrated in figure 2 . The following gives a brief description of the key parameters in the landfill model. 


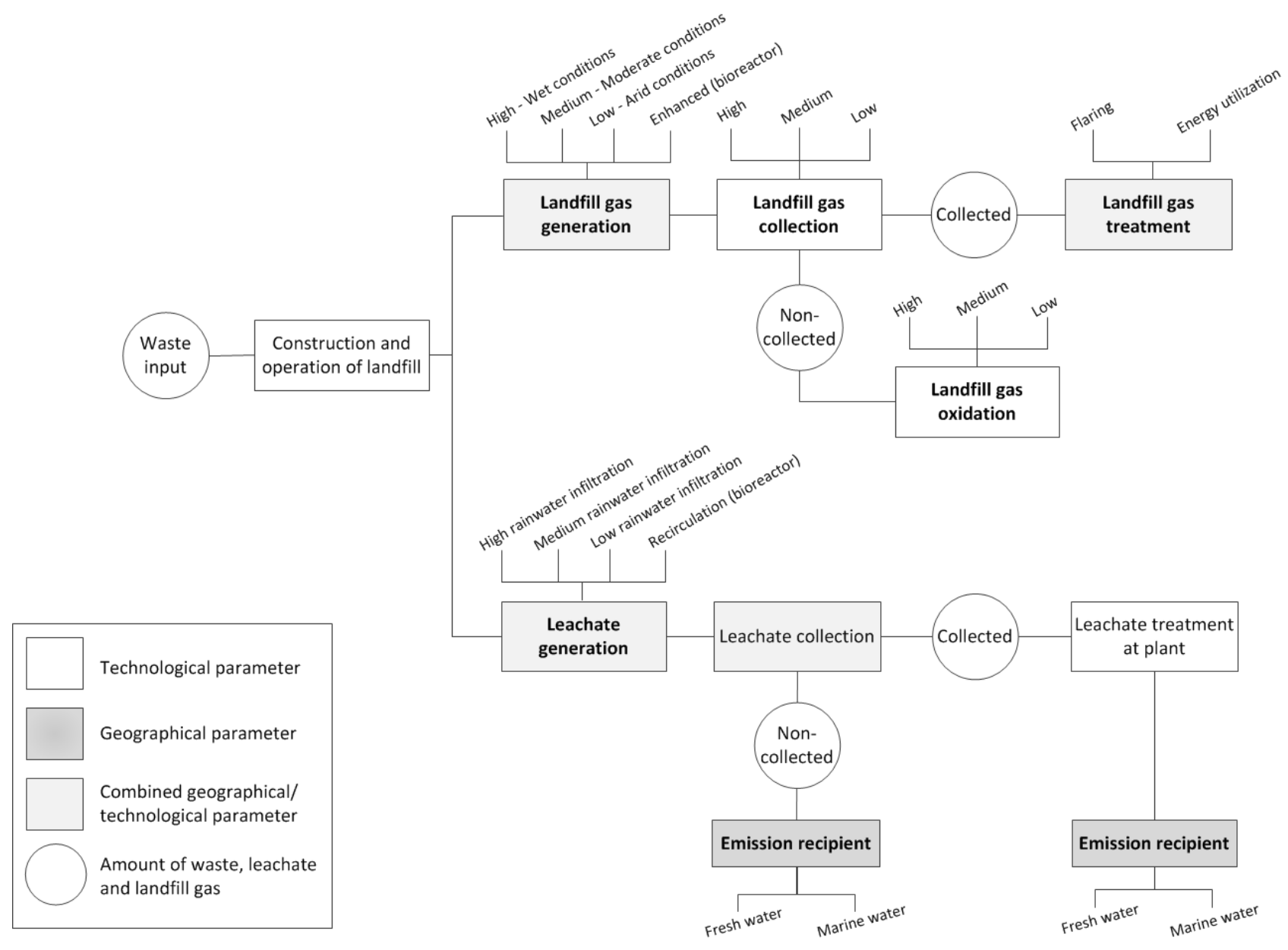

Figure 2 Landfill model diagram consisting of seven landfill gas and leachate process modules, and specification of the leachate emission recipient. It is indicated if a process module is controlled by predominantly technological, geographical, or combined geographical/technological key parameters. Key parameters were varied for landfill gas generation, gas collection, and treatment as well as leachate generation and leachate emission recipient.

Landfill gas generation was estimated using a material-specific first order decay model. Materialspecific decay rates and methane potentials varied with landfill moisture content and temperature. For bioreactor landfills, gas generation was modeled with higher decay rates representing enhanced degradation. Moisture content of the waste partly depends on the initial moisture content of the disposed waste and rainwater infiltration and percolation through the landfill cover, the latter being influenced by the precipitation level in the region and the landfill cover permeability (Yang et al. 2015). Therefore, moisture content was defined as a combined technological and geographical parameter. Oxidation of non-collected methane depends on the retention time of the gas in the top cover (Christensen 2011). The rate of landfill gas collection and extraction influences the retention 
time of non-collected landfill gas, why the oxidation rate was paired with the landfill gas collection rate. Both landfill gas collection and oxidation are considered predominantly technological parameters, because they are influenced by the design of the landfill gas extraction wells, liners and top cover (Christensen 2011). The carbon dioxide from oxidized methane was assumed carbonneutral, with the reasoning that $\mathrm{CO}_{2}$ emissions originating from the degradation of biogenic waste materials (food and yard waste) do not have a net contribution to global warming, whereas carbon sequestering was included for stored biogenic carbon in the landfill (Brandão et al. 2013).

Two landfill gas treatment options were included: energy utilization and flaring. Energy utilization includes the generation of electricity, and system expansion was applied to include downstream savings from substituted marginal energy. The marginal energy technologies were coal-based Danish marginal electricity (Behnke 2006; DONG Energy 2007a, 2007b, 2007c) and thermal energy produced from a mix of waste, biofuels, surplus heat and oil (Energistyrelsen 2012). The choice of marginal electricity mix is a debated topic, and choosing other energy sources than fossil fuels could change the results. However, as mentioned previously, variation of background modeling choices is not considered. The flaring process was modeled at $99 \%$ methane oxidation efficiency, and the oxidation of other substances was also included. Selection of the suitable landfill gas treatment at site is influenced by the amount of landfill gas being generated, technological level of the landfill facility, and external energy system; landfill gas treatment is thus controlled by combined geographical and technological parameters.

Leachate generation was modeled as a function of net infiltration and percolation of rainwater through the landfill layers. The moisture content of Danish waste is below the field capacity of landfills, in which case the moisture will not contribute to leachate formation; in regions with a high amount of organic content in the waste this might not be the case (Yang et al. 2015). Therefore, in this model the leachate generation is a function of net infiltration depending on precipitation, temperature and permeability of the landfill cover, damage to which will decrease permeability and increase rainwater infiltration (Yang et al. 2015). Thus, leachate generation is a combined geographical and technological parameter. Leachate treatment was modeled with a fixed wastewater treatment process. The leachate discharge, of both non-collected leachate and leachate after treatment, was modeled to a freshwater or marine water recipient. The local water body is a geographical parameter depending on the specific location of the landfill.

\section{Grouping relative to specificity of study context}


The grouping of the 52 landfill datasets is depicted in figure 3. The left-hand side expresses six levels of specificity of the technological and geographical context, corresponding to step A in figure 1. The top level specifies the waste treatment category, here an engineered landfill, where the technology type and location is unknown. In the second level, the technology type is known, here a bioreactor or conventional reactor landfill, but the regional and specific location as well as landfill gas collection, oxidation, and treatment is unknown. In the third level, the regional location - and therefore the amount of landfill gas and leachate generation - is known, but the specific location as well as landfill gas collection, oxidation, and treatment is unknown. In the fourth level the specific location, i.e. freshwater or marine recipient, is known but the landfill gas collection, oxidation, and treatment is unknown. Finally, the fifth level specifies the landfill gas collection and oxidation efficiencies, and the sixth level specifies the landfill gas treatment method. Thus, each level expresses a degree of knowledge about the system, and the next level involves an additional known parameter. The order of the levels of specification is not universal; for example, in other situations the geographical location may be known before the type of landfill. Also, the landfill gas treatment method could be known as one of the first parameters, but it is here placed at the sixth level of specification, because the choice of gas treatment partly depends on the amount of gas being generated and collected, i.e. on the fifth specification level in figure 3.

The hierarchy diagram in figure 3 shows the groupings per specification level, corresponding to step B1 in figure 1. Corresponding to step B2 in figure 1, LCI data was collected and landfill datasets were generated representing these groups. All 52 datasets belonged in the top group, 36 datasets belonged in the bioreactor and conventional reactor groups, and 16, 6, 12, and 18 datasets belonged in the landfill gas and leachate generation groups. For the bottom three levels, the datasets were less aggregated and sometimes equal to a single dataset, due to the high level of specificity of the study context. 

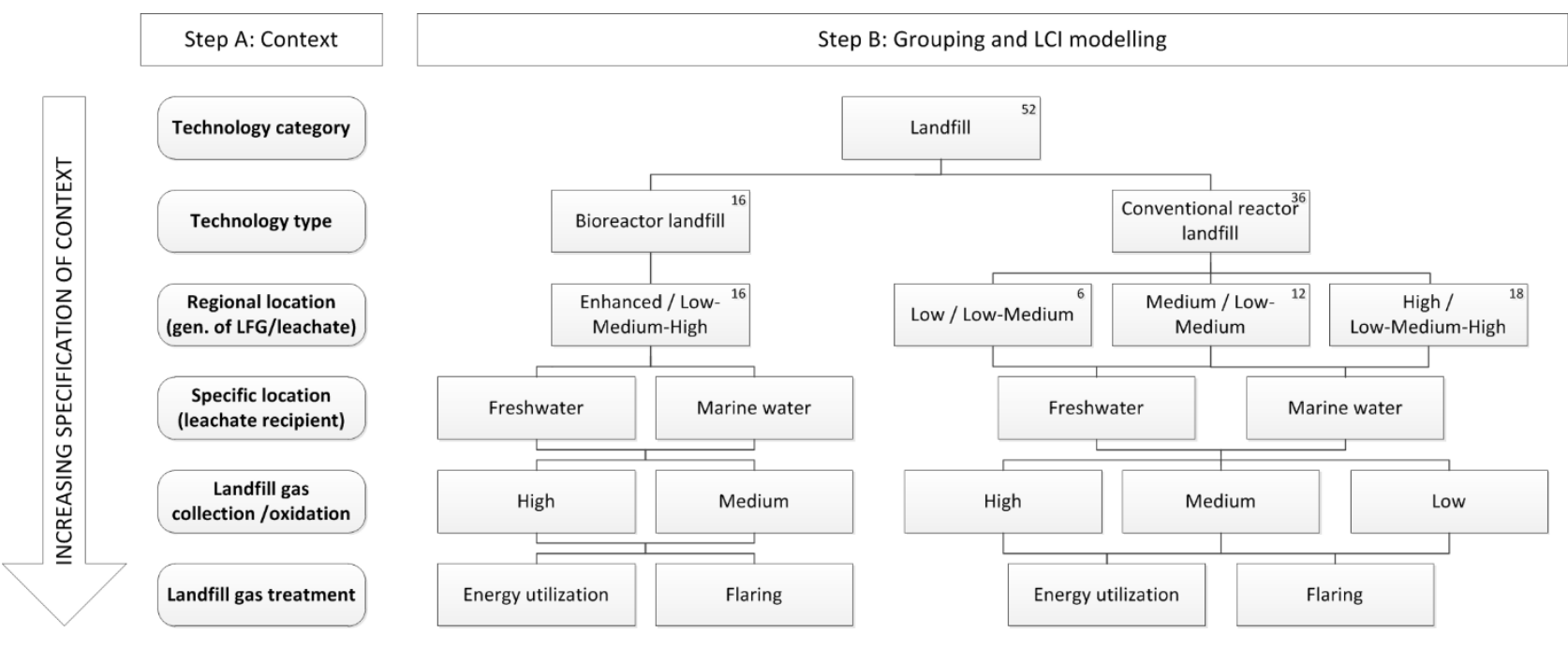

Figure 3 Left-hand side: six levels of context specificity with increasing specification from top to bottom (step A in figure 1). Levels 2 to 6 specify an additional parameter compared to the previous level. Hierarchy diagram: Grouping and LCI modeling of likely landfill configurations and geographical locations per specification level (step B in figure 1). The terms "high," “medium,” and "low” refer to the parameter alternatives in figure 2. LCI = life cycle inventory; LFG = landfill gas; gen. = generation.

Finally, potential impacts were calculated and sets of results were gathered according to the groups in figure 3, corresponding to step C in figure 1. Min-max intervals were calculated including mean values. Applying the min-max interval reflects a lack of information on the probability of the applicability of each landfill configuration within each group, i.e. a lack of information about the more likely waste treatment scenario. Some mean values of the min-max intervals will be weighted towards a certain preference, due to a larger frequency of some technology configurations and climatic conditions in a group. Such mean values are asymmetric and the corresponding min-max intervals are non-uniform.

\section{Results and discussion}

\section{Potential impacts relative to specificity of study context}

The first objective of this article to determine the importance of representative LCI modeling relative to the study context, is addressed in this section. In figure 4 and 5, the LCA results are plotted as a function of increasing specificity of the technological and geographical study context, and the six specification levels in figure 3 are shown on the $\mathrm{x}$-axis. Characterized potential impacts are shown for two example categories: Global warming (GW) and human toxicity, carcinogenic 
(HTc). Results for all 14 impact categories are given in Supporting Information, Excel file. GW and HTc impacts were chosen because they are directly affected by the two main impact contributors from landfilling: landfill gas and leachate, as identified in previous studies (e.g., Manfredi et al. 2010). Landfilling contributes to other environmental impacts due to the related fuel and material use and the substances emitted with leachate (dissolved and suspended substances) and landfill gas (volatile degradation products), directly and after treatment. To ease interpretation of figure 4, some results with similar key parameters are circled and labeled. The variations in the LCIs of the 52 landfill datasets - concerning generation, treatment and emission of landfill gas and leachate - led to variations in results (figure 4). Landfills that flared the collected landfill gas did not receive savings from avoided marginal energy and therefore exhibit positive net GW impacts (figure 4). The background data on marginal energy were important for the landfill technologies with landfill gas collection and utilization, as the avoided marginal energy production led to relatively large savings for some impact categories, namely GW (avoided fossil $\mathrm{CO}_{2}$ emissions), photochemical oxidant formation (avoided $\mathrm{NO}_{\mathrm{x}}$ emissions) and fossil resource depletion (avoided coal use). Impact categories mainly influenced by leachate emissions were human toxicity, ecotoxicity and eutrophication. Figure 4 clearly shows that the specification of the leachate recipient influences the HTc results. This is due to the larger HTc impact factors for freshwater releases compared to marine water releases (Rosenbaum et al. 2008). Figure 5 provides an example of the specification of a bioreactor landfill starting from landfill category level. Comparing the GW and HTc results in figure 5 indicates that the importance of LCI data is both a function of the study context and impact categories of interest.

The general trend in figure 4 is a shift from min-max intervals to point values from left to right, with the number of representative landfill datasets decreasing with increasing specificity of the study context. For GW, the global maximum and minimum value - equal to the maximum and minimum of the largest interval - had an absolute difference of $750 \mathrm{~kg} \mathrm{CO}$-eq. (-457 to $293 \mathrm{~kg}$ $\mathrm{CO}_{2}$-eq.), and for HTc the global maximum value was 45 times larger than the global minimum value (3.79-9 to $1.70^{-7}$ CTUh). A previous study found a GW range from -209 to $162 \mathrm{~kg}$ CO2-eq. per ton landfilled waste (Manfredi et al. 2009), which is within the maximum interval of this case study. Environmental savings in GW are due to the stored biogenic carbon in the landfill and marginal energy substitution from landfill gas utilization. If the marginal electricity and heat mixes had been renewable sources, the GW savings for the landfill technologies utilizing landfill gas would have been smaller. The general trend of decreasing result ranges from left to right in figure 4 
was less evident for HTc. The HTc ranges at the right-hand side of figure 4 are due to the aggregation of semi-high and high leachate generation in the LCI model; an example of the influence of a foreground modeling choice. The HTc impacts should be seen in light of the chosen temporal coverage of 100 years and would have been larger for longer time scales; yet, the increase in impacts would not change the relative results of the landfill datasets, due to the fixed waste input in the case study. For an overview, table 1 shows the normalized global minimum, maximum and mean values for all 14 impact categories.

In figure 4 and 5, some min-max intervals were non-uniform with unsymmetrical means. For these, it would be invalid to assume symmetry around the mean value as the distribution of representative technologies is skewed due to a larger frequency of some technology configurations and climatic conditions. An example of such a non-uniform interval is the largest min-max interval for HTc, where different frequencies of landfills with varying leachate management caused the asymmetry. Hence, to obtain representative result intervals and mean values, information should be collected about - not only the range of parameter values - but also the frequency of the parameter values expected within the boundaries of the scope of study. This finding is in line with the concept of weighted averages, previously investigated in Henriksson et al. (2013) and Levis and Barlaz (2011).

Information of decisive parameters are needed to prioritize further data collection as part of the iterative nature of LCA. The example in figure 5 illustrates decisive parameters of landfill modeling, being those specifications reducing the result range of GW and HTc. For GW, decisive parameters were mainly the landfill type and landfill gas management. For HTc, decisive parameters were mainly the leachate generation and leachate recipient. Knowledge about the variability of these parameters is critical for the reliability of the study. The example in figure 5 also indicates that even for a relatively specific study context - where the landfill type is known (bioreactor landfill) - variation of rainwater infiltration, waste degradation rates, and landfill gas treatment is still relevant. Supporting Information section 3 contains a summary of decisive parameters for all 14 impact categories.

The second objective of this article, to determine whether and how the goal and scope of the study should be refined based on the obtained data, is addressed in the following two sections. Two principal situations of unrepresentative data choices are discussed, namely situation A) where a sitespecific dataset is used to represent a general engineered landfill with unknown location and 
technology configuration, and situation B) where a horizontally aggregated dataset is used to represent a specific conventional reactor landfill with known location and technology configuration, yet still with local variabilities.
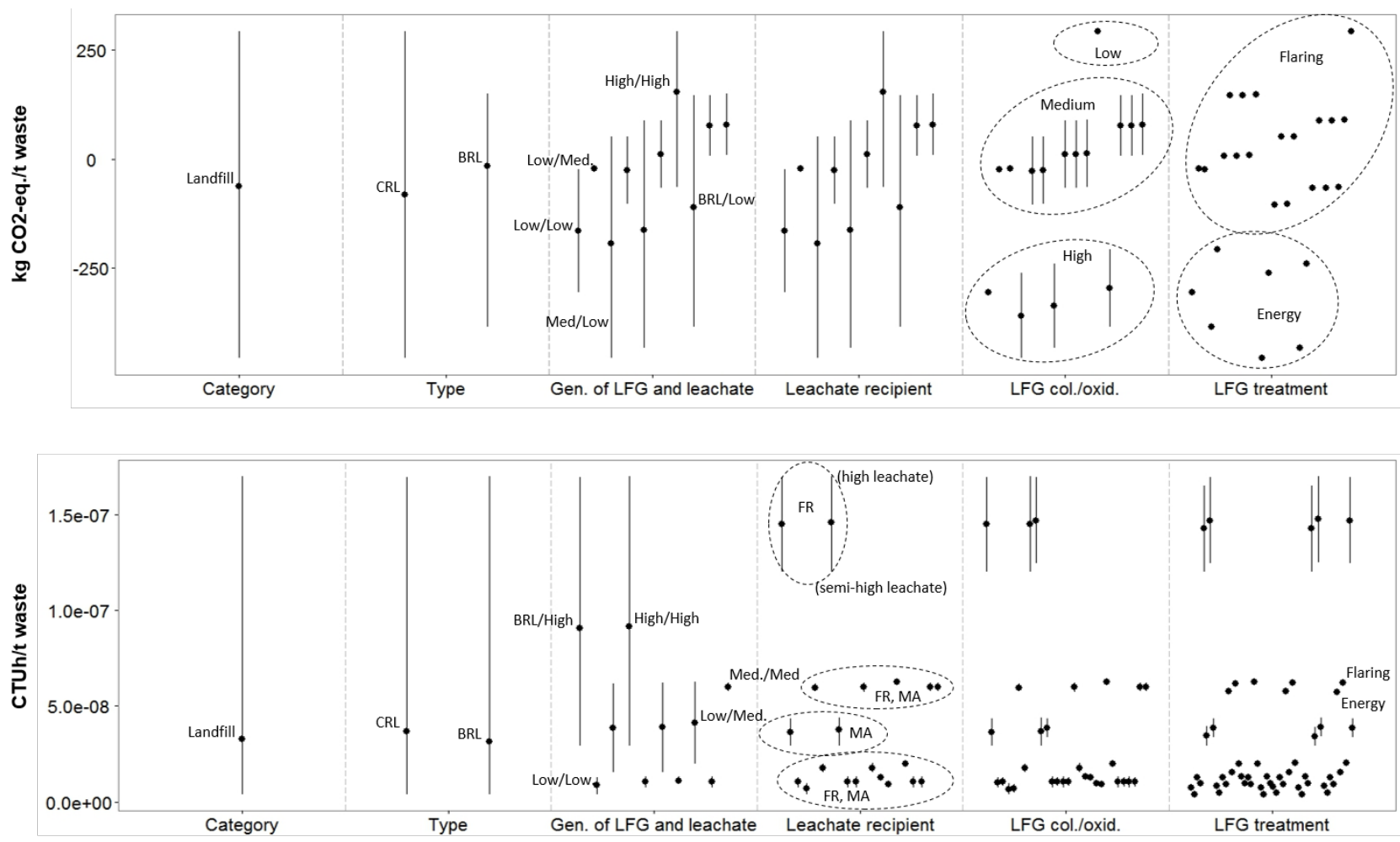

Increasing specification of context of study

Figure 4 Global warming potential (given in kg CO2-equivalents) and human toxicity, carcinogenic, potential (given in comparative toxic units for humans) as a function of the specificity of the study context. The labels on the x-axis equal the six specification levels in figure 3. Results expressing similar key parameters are circled and the parameter is written. "High," "medium," and "low" refer to the parameter alternatives in figure 2. BRL = bioreactor landfill; CRL = conventional reactor landfill; med. = medium; FR = freshwater; $\mathrm{LFG}=$ landfill gas; $\mathrm{MA}=$ marine water.

Table 1 Global minimum, maximum and mean LCA result values for all 14 impact categories. The values are normalized to units of Person Equivalents. Applied normalization references are shown in Supporting Information section 1.1.

\begin{tabular}{lllllllllllllll}
\hline$*$ & GW & OD & HTc & HTnc & PM & IR & POF & TA & TE & FE & ME & ET & RDfos & RD \\
\hline Min & $-5.6^{-2}$ & $7.1^{-4}$ & $7.0^{-5}$ & $-8.6^{-4}$ & $-3.3^{-3}$ & $-9.0^{-5}$ & $-2.3^{-3}$ & $-4.2^{-4}$ & $1.7^{-3}$ & $-5.3^{-7}$ & $1.9^{-3}$ & $-5.5^{-3}$ & $-2.4^{-2}$ & $-1.7^{-5}$ \\
Max & $3.6^{-2}$ & $3.1^{-3}$ & $3.1^{-3}$ & $10^{-3}$ & $1.1^{-3}$ & $9.0^{-6}$ & $7.5^{-5}$ & $1.6^{-3}$ & $8.9^{-3}$ & $1.6^{-6}$ & $10^{-3}$ & $3.1^{-1}$ & $3.8^{-3}$ & $2.7^{-5}$ \\
Mean & $-4.5^{-3}$ & $2.0^{-3}$ & $7.8^{-4}$ & $2.6^{-3}$ & $-5.1^{-4}$ & $-2.5^{-5}$ & $5.5^{-3}$ & $6.7^{-4}$ & $4.2^{-3}$ & $8.9^{-7}$ & $4.7^{-3}$ & $9.5^{-2}$ & $-5.8^{-3}$ & $2.1^{-5}$ \\
\hline
\end{tabular}

*GW (climate change,), OD (stratospheric ozone depletion), HTc (human toxicity, carcinogenic), HTnc (human toxicity, non-carcinogenic), PM (particulate matter), IR (ionizing radiation), POF (photochemical ozone formation), TA (terrestrial acidification), TE (terrestrial eutrophication), FE (freshwater eutrophication), ME (marine eutrophication), ET (freshwater ecotoxicity), RDfos (fossil resources depletion), RD (metals/minerals depletion) 

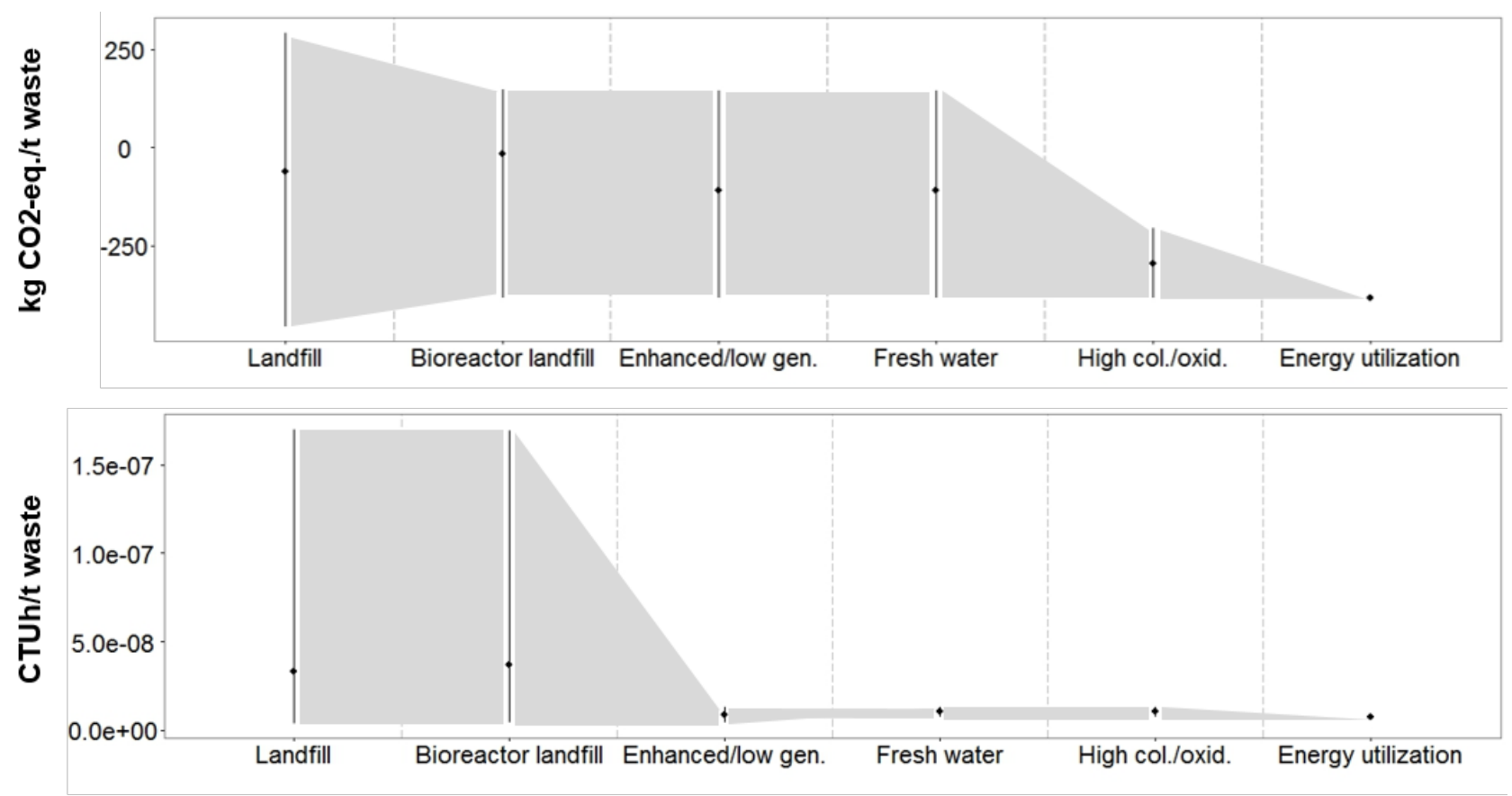

Example of increased context specification

Figure 5 Global warming potential (given in kg CO2-equivalents) and human toxicity, carcinogenic, potential (given in comparative toxic units for humans) as a function of the specificity of the study context. The diagram is an example of specification of a certain bioreactor landfill, with the actual specifications explained on the x-axis.

\section{Situation A: Site-specific dataset to represent non-specific study context}

Situation A is illustrated in figure 6, where A1 expresses the obtained LCA results based on the available data, and A2 illustrates the hypothetical LCA results if appropriate data, representing the target processes, had been used. The result interval corresponding to A2 (-457 to $293 \mathrm{~kg} \mathrm{CO}_{2}$-eq.) is 3.8 times larger than the result interval corresponding to $\mathrm{A} 1$ (-457 to $-261 \mathrm{~kg} \mathrm{CO}$-eq.). The interval of A1 lies within the interval of A2, but only covers the lower fraction of the interval of A2. Therefore, the interval of A1 underestimates the variation and potential impacts from landfilling. Figure 6 clearly shows that selecting specific data (A1) involves a deselection of alternative technology configurations and geographic locations (range of possibilities in A2). Deselections may stem from deliberate LCI modeling choices or be predefined in datasets or models (Gentil et al. 2010). An issue arises especially when deselections are not in line with the goal and scope definition, and are unknown or, even worse, ignored by the LCA practitioner. 
It is recommended to either refine the goal and scope of the study towards being more sitespecific, or to estimate an additional spread around A1 to better fit the target data of A2. If quantitative information about the spread of the parameter values are unavailable, the spread may be estimated based on expert judgement, e.g. possibility theory as fuzzy sets (Clavreul et al. 2013). One should not by default assume that the available data equal the mean or median of the distribution, since - with the mean of A1 as an example - such an assumption would give an interval covering an area below the minimum value of the target interval A2, causing additional unrepresentativeness. Alternatives to expert judgement include using default uncertainty factors to estimate additional uncertainties, based on an assessment of representativeness and other data quality aspects (Ciroth et al. 2013). However, authors have criticized the conversion of data quality to uncertainty factors for being inaccurate in their representation of the processes in question (Lloyd and Ries 2007).

\section{Situation B: Aggregated dataset to represent specific study context}

Situation B is illustrated in figure 6, where B1 expresses the obtained LCA results based on the available data, and B2 illustrates the hypothetical LCA results if appropriate data, representing the target processes, had been used. The result interval of B1 is wider than that of B2, and is accurate in the sense that the target interval and mean value of B2 lie within the range of possibilities for B1. However, the attention should be paid to the mean value of B1, because often only the mean or median of aggregated datasets are available to LCA practitioners. The mean value of B1 overestimates the target mean of B2 because B1 includes lower performing landfill technologies than those included in the interval of B2. Thus, the entire interval of B1 must be included to be able to cover B2. Including the entire interval of B1, however, leads to the need of refining the goal and scope definition according to the available data. The refined goal and scope imply a broader technological and geographical coverage of the study, and lower level of knowledge about the system. Refining the scope is in line with the standards (ISO 2006), but the lessening of scope specificity is probably only rarely done in actual LCA studies often based on single technology choices.

Situation B might occur when the LCA practitioner experiences data gaps and ends up using aggregated data as a proxy (Björklund 2002). In this case study, the mean value of B1 was the result of aggregation across different landfill technologies and geographical locations, whereas the variation of B2 was due to uncertainty about one discrete data choice, namely landfill gas treatment. 
The importance of information about the spread around horizontal averages have been studied for more than 20 years (Smet and Stalmans 1996; Meron et al. 2016). However, there is generally no information about the spread around aggregated data from databases, e.g. ecoinvent (Ecoinvent 2015) and European Life Cycle Database (ELCD 2017), possibly because this information is held by the original data provider or the dataset stem from only one source. Thus, the LCA practitioner must quantify the potential spread, e.g. based on expert judgement and data quality assessment, as mentioned for situation A. Another approach would be to go and collect primary data, but this would require additional resources in terms of time and money.
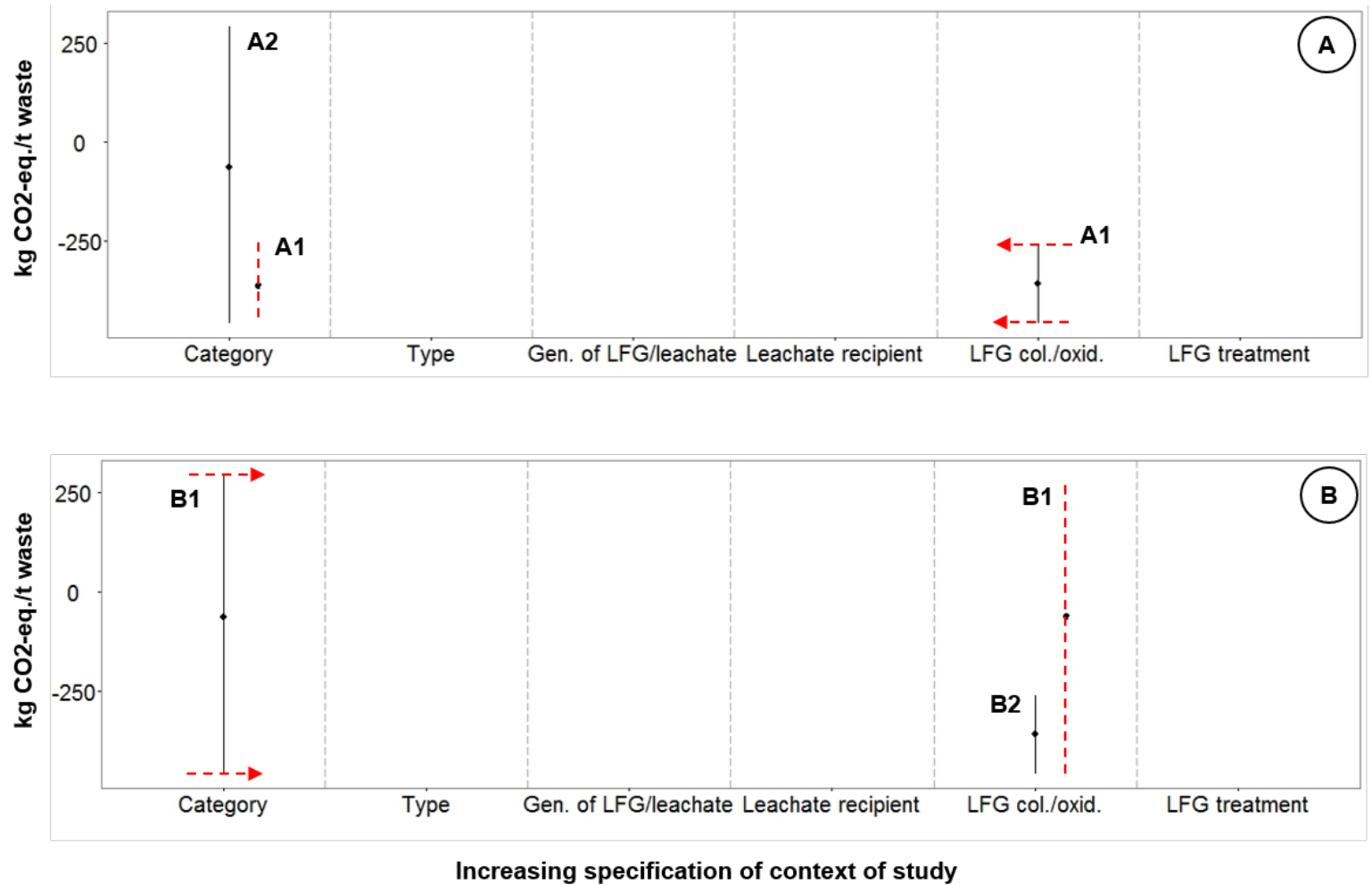

- - -.. - Interval and mean of obtained data (A1, B1)

Target interval and mean (A2, B2)

Figure 6 Global warming potential (given in kg CO2-equivalents) as a function of the specificity of the study context. Two situations (A and B) of unrepresentative data choices in LCA are sketched. Top diagram: A1 expresses the interval and mean value of the obtained data (represent an efficient conventional reactor landfill), while A2 expresses the target interval and mean value (an average engineered landfill). Bottom diagram: B1 expresses the interval and mean value of the obtained data (represent an average engineered landfill), while B2 expresses the target interval and mean value (an efficient conventional reactor landfill). LCA = life cycle assessment; LFG = landfill gas.

\section{Conclusion}


The importance of inherent technology variations was evaluated through modeling these as a function of the specificity of the study context, in terms of technology configurations and climatic conditions. A landfill case study was conducted by building 52 discrete landfill datasets, grouping these to represent different technology options and geographical sites, calculating potential impacts, and generating min-max intervals representing the groupings. The results showed decreasing minmax intervals with increasing specificity of the study context, highlighting that compatibility between the study context and the LCI model is critical. Thus, this study quantitatively demonstrated the influence of representative modeling on LCA results, emphasizing the need for iterative modeling and goal and scope refining. The results demonstrated the relevance of process variations at a relatively high detail level, e.g. the influence of precipitation and cover permeability on landfill gas generation and collection. Therefore, it is concluded that detailed understanding of the waste treatment process is necessary to ensure that the data choices are consistent with the boundaries of the defined goal and scope of the study. The quantification of representative modeling, provided in this study, is relevant for waste treatment technologies and other technical domains for which local conditions and technology configurations have a large influence on the environmental performance.

Acknowledgments This research was supported by the Department of Environmental Engineering at the Technical University of Denmark, through a scholarship from the R98 foundation. We would like to thank Thomas Christensen (Technical University of Denmark), Morton Barlaz and James Levis (North Carolina State University) for comments to earlier versions of the manuscript, as well as the reviewers for their valuable comments. 


\section{References}

Astrup, T., D. Tonini, R. Turconi, and A. Boldrin. 2014. Life cycle assessment of thermal Waste-to-Energy technologies: Review and recommendations. Waste Management 37: 104-115. http://dx.doi.org/10.1016/j.wasman.2014.06.011.

Bawden, K.R., E.D. Williams, and C.W. Babbitt. 2016. Mapping product knowledge to life cycle inventory bounds: A case study of steel manufacturing. Journal of Cleaner Production 113: 557-564. http://dx.doi.org/10.1016/j.jclepro.2015.10.014.

Behnke, K. 2006. Notat om deklaration af fremtidigt elforbrug, (Memorandum on the future electricity consumption, in Danish). Denmark.

Bisinella, V., K. Conradsen, T.. H. Christensen, and T.F. Astrup. 2016. A global approach for sparse representation of uncertainty in Life Cycle Assessments of waste management systems. International Journal of Life Cycle Assessment.

Björklund, A. 2002. Survey of approaches to improve reliability in LCA. International Journal of Life Cycle Assessment 7: 64-72.

Brandão, M., A. Levasseur, M.U.F. Kirschbaum, B.P. Weidema, A.L. Cowie, S.V. Jørgensen, M.Z. Hauschild, D.W. Pennington, and K. Chomkhamsri. 2013. Key issues and options in accounting for carbon sequestration and temporary storage in life cycle assessment and carbon footprinting. The International Journal of Life Cycle Assessment 18(1): 230-240. http://link.springer.com/10.1007/s11367-012-0451-6.

Canals, L.M.I., A. Azapagic, G. Doka, D. Jefferies, H. King, C. Mutel, T. Nemecek, et al. 2011. Approaches for addressing life cycle assessment data gaps for bio-based products. Journal of Industrial Ecology 15(5): 707-725.

Christensen, T.H. 2011. Solid Waste Technology and Management. Ed. by Thomas H. Christensen. 2nd ed. Blackwell Publishing Ltd. 
Ciroth, A., S. Muller, and B. Weidema. 2013. Empirically based uncertainty factors for the pedigree matrix in ecoinvent. International Journal of Life Cycle Assessment.

Clavreul, J., H. Baumeister, T.H. Christensen, and A. Damgaard. 2014. An environmental assessment system for environmental technologies. Environmental Modeling \& Software 60: 18-30. http://linkinghub.elsevier.com/retrieve/pii/S1364815214001728.

Clavreul, J., D. Guyonnet, D. Tonini, and T.H. Christensen. 2013. Stochastic and epistemic uncertainty propagation in LCA. International Journal of Life Cycle Assessment 18(7): 1393-1403.

Damgaard, A., C. Riber, T. Fruergaard, T. Hulgaard, and T.H. Christensen. 2010. Life-cycle-assessment of the historical development of air pollution control and energy recovery in waste incineration. Waste Management 30(7): 1244-1250. http://dx.doi.org/10.1016/j.wasman.2010.03.025.

DONG Energy. 2007a. Esbjergvœrket. Grønt regnskab 2006 (Esbjerg power plant. Green Account 2006, in Danish).

DONG Energy. 2007b. Asnæesvœrket. Grønt regnskab 2006 (Asnæes power plant. Green Account 2006, in Danish).

DONG Energy. 2007c. Stigsnæesvcerket. Grønt regnskab 2006 (Stigsnæes power plant. Green Account 2006, in Danish).

Ecoinvent. 2015. Ecoinvent database. http://www.ecoinvent.org. Accessed March 9, 2017.

ELCD. 2017. ELCD Database. http://eplca.jrc.ec.europa.eu/ELCD3/. Accessed March 9, 2017.

Energistyrelsen. 2012. Forudsætninger for samfundsøkonomiske analyser på energiområdet.

European Commission. 2010. International Reference Life Cycle Data System (ILCD) Handbook: Analysing of existing Environmental Impact Assessment methodologies for use in Life Cycle Assessment. European Commission-Joint Research Centre-Institute for Environment and Sustainability. Ispra, Italy.

Gentil, E.C., A. Damgaard, M. Hauschild, G. Finnveden, O. Eriksson, S. Thorneloe, P.O. Kaplan, et al. 2010. Models for waste life cycle assessment: Review of technical assumptions. Waste Management 30(12): 
2636-2648. http://dx.doi.org/10.1016/j.wasman.2010.06.004.

Gregory, J.R., A. Noshadravan, E.A. Olivetti, and R.E. Kirchain. 2016. A Methodology for Robust Comparative Life Cycle Assessments Incorporating Uncertainty. Environmental Science and Technology 50(12): 6397-6405.

Harst, E. Van der and J. Potting. 2014. Variation in LCA results for disposable polystyrene beverage cups due to multiple data sets and modeling choices. Environmental Modeling and Software 51: 123-135. http://dx.doi.org/10.1016/j.envsoft.2013.09.014.

Heijungs, R. 1996. Identification of key issues for further investigation in improving the reliability of lifecycle assessments. Journal of Cleaner Production 4(3-4): 159-166.

Heijungs, R. and M. a J. Huijbregts. 2004. A review of approaches to treat uncertainty in LCA. iEMSs 2004 International Congress: 8. http://www.iemss.org/iemss2004/pdf/lca/heijarev.pdf.

Heijungs, R. and R. Kleijn. 2001. Numerical Approaches Towards Life Cycle Interpretation. The International Journal of Life Cycle Assessment 6(3): 141-148.

Henriksson, P.J.G., J.B. Guinée, R. Heijungs, A. De Koning, and D.M. Green. 2013. A protocol for horizontal averaging of unit process data - Including estimates for uncertainty. International Journal of Life Cycle Assessment 19(2): 429-436.

IPCC. 2007. Climate Change 2007: Synthesis Report. Contribution of Working Groups I, II and III to the Fourth Assessment Report of the Intergovernmental Panel on Climate Change.

ISO. 2006. ISO 14044 - Environmental management - Life cycle assessment - Requirements and guidelines.

Laurent, A., J. Clavreul, A. Bernstad, I. Bakas, M. Niero, E. Gentil, T.H. Christensen, and M.Z. Hauschild. 2014. Review of LCA studies of solid waste management systems - Part II: Methodological guidance for a better practice. Waste Management 34(3): 589-606. http://dx.doi.org/10.1016/j.wasman.2013.12.004.

Levis, J.W. and M. Barlaz. 2011. Is biodegradability a desirable attribute for discarded solid waste? 
Environmental Science and Technology 45: 5470-5476.

Lloyd, S.M. and R. Ries. 2007. Characterizing, Propagating and Analyzing Uncertainty in Life-Cycle Assessment - A Survey of Quantitative Approaches. Journal of Industrial Ecology 11(1).

Manfredi, S., D. Tonini, and T.H. Christensen. 2010. Contribution of individual waste fractions to the environmental impacts from landfilling of municipal solid waste. Waste Management 30(3): 433-440. http://linkinghub.elsevier.com/retrieve/pii/S0956053X09003717.

Manfredi, S., D. Tonini, T.H. Christensen, and H. Scharff. 2009. Landfilling of waste: accounting of greenhouse gases and global warming contributions. Waste Management \& Research 27(8): 825-836. http://wmr.sagepub.com/content/27/8/789.abstractN2 - Important greenhouse gas (GHG) emissions related to waste incineration and co-combustion of waste were identified and considered relative to critical aspects such as: the contents of biogenic and fossil.

Meron, N., V. Blass, Y. Garb, Y. Kahane, and G. Thoma. 2016. Why going beyond standard LCI databases is important: lessons from a meta-analysis of potable water supply system LCAs. International Journal of Life Cycle Assessment: 1-14.

Merrild, H., A. Damgaard, and T.H. Christensen. 2008. Life cycle assessment of waste paper management: The importance of technology data and system boundaries in assessing recycling and incineration. Resources, Conservation and Recycling 52(12): 1391-1398.

Møller, J., M. Jensen, M. Kromann, T. Lund Neidel, J. Bjørn Jakobsen, B. Jakobsen, and J. Møller. 2013. Miljø- og samfundsøkonomisk vurdering af muligheder for øget genanvendelse af papir, pap, plast, metal og organisk affald fra dagrenovation. Miljøprojekt 1458. Miljøprojekt Nr. 1458. Miljøministeriet.

Olivetti, E., S. Patanavanich, and R. Kirchain. 2013. Exploring the viability of probabilistic underspecification to streamline life cycle assessment. Environmental Science and Technology 47(10): 52085216.

Riber, C., C. Petersen, and T.H. Christensen. 2009. Chemical composition of material fractions in Danish 
household waste. Waste Management 29(4): 1251-1257.

http://linkinghub.elsevier.com/retrieve/pii/S0956053X08003322.

Rosenbaum, R.K., T.M. Bachmann, L.S. Gold, M.A.J. Huijbregts, O. Jolliet, R. Juraske, A. Koehler, et al. 2008. USEtox - the UNEP-SETEC toxicity model: recommended characterisation factors for human toxicity and freshwa-ter ecotoxicity in life cycle impact assessment. International Journal of Life Cycle Assessment(13): 532-546.

Smet, B.D. and M. Stalmans. 1996. LCI Data and Data Quality - Thoughts and Considerations. International Journal of Life Cycle Assessment 1(2): 96-104.

UNEP. 2011. Global Guidance Principles for Life Cycle Assessment Databases. Paris: SETAC Press.

Weidema, B.P. and M.S. Wesnæs. 1996. Data quality management for life cycle inventories—an example of using data quality indicators. Journal of Cleaner Production 4(3-4): 167-174.

Yang, N., A. Damgaard, P. Kjeldsen, L.-M. Shao, and P.-J. He. 2015. Quantification of regional leachate variance from municipal solid waste landfills in China. Waste Management 46: 362-372. http://linkinghub.elsevier.com/retrieve/pii/S0956053X15301252.

About the authors Trine Henriksen is a PhD student at the Technical University of Denmark (DTU) in Lyngby, Denmark. Anders Damgaard is a Senior Researcher at DTU in Lyngby, Denmark. Thomas F. Astrup is a Professsor at DTU in Lyngby, Denmark. 